\title{
Commentary
}

See article on page 394

\section{Who needs a doctor for IBS?}

On page 394, Talley and colleagues report the results of a population based study which attempted to explain health care seeking for irritable bowel syndrome (IBS). Of their sample, $13 \%$ had IBS by Manning criteria and of these $73 \%$ had sought medical care for abdominal pain or discomfort. Those who had and had not sought medical care were compared-severity and duration of the abdominal pain were independently associated with health care seeking but psychological status and history of childhood abuse were not.

This finding may be surprising as previous work in the USA had concluded that symptoms of psychological distress are unrelated to IBS but related to health care seeking $^{1}$ and this view is often quoted in the literature. Talley et al's study seems to contradict this finding. How does it compare with other research?

Two careful studies used a diary to record bowel symptoms. Both found that abdominal pain and diarrhoea differentiated IBS consulters from non-consulters. ${ }^{23}$ In the study by Heaton et al, the likelihood of consulting a physician with IBS showed a clear linear trend depending on the number of IBS symptoms reported (especially abdominal pain)..$^{3}$

With regard to psychological symptoms, Drossman and colleagues used multivariate analysis. Even when the bowel symptoms were controlled, consulters had higher depression scores on the MMPI, and greater illness behaviour questionnaire scores than non-consulters. ${ }^{2}$ In the study from the United Kingdom, ${ }^{4}$ higher anxiety and depression scores were found in consulters than in non-consulters. Welch et $a \bar{l}$ found that both IBS consulters and non-consulters had raised scores on the symptom check list of neurotic symptoms, compared with normal subjects, suggesting that psychological distress may be associated with IBS symptoms themselves, rather than treatment seeking.

Other work from the United Kingdom has indicated the different results obtained by questionnaire surveys and research interviews. ${ }^{67}$ The former did not produce a clear result, whereas an intensive study of consulting and non-consulting subjects with IBS showed that the consulters had significantly more visible abdominal distension, more severe pain, more serious health concerns (including the possibility of cancer), increased anxiety and depression scores, and a higher negative life event score. On regression analysis, severity of pain and health anxiety explained $85 \%$ of the variance between the two groups.

Thus, the finding reported by Talley et al that pain severity is the principle predictor of health care seeking fits well with the findings of three previous studies. ${ }^{237}$ Interpretation of the psychosocial aspects requires careful consideration of potential methodological problems.

Talley et al's study was a postal survey using self administered questionnaires, which leaves uncertainties regarding precise diagnosis of IBS and abuse items. With regard to the former, the definition of IBS provided a prevalence of $13 \%$ which is consistent with other studies using fairly tight criteria for diagnosis. However, the threshold for childhood sexual abuse was quite low as $23 \%$ were categorised as having experienced such abuse. This is comparable with Talley's previous study in the USA $(21.8 \%)^{8}$ but contrasts notably with the figures of $9 \%$ to $13 \%$ reported by interview studies. ${ }^{9} 10$

The response rate (64\%) was somewhat low-the non-responders could have been biased towards more or less psychological distress or prior childhood abuse, or both.

Of the subjects with IBS, $73 \%$ had sought medical care for abdominal pain or discomfort in the prior year, leaving only 26 IBS non-health care seekers. This compares with studies from the United Kingdom in which $33-55 \%$ of population based samples of subjects with IBS have consulted - the differences may reflect different samples or different health care systems.

The group of non-consulters may have been too small to demonstrate real differences between the groups (type II error). For example, the mean GHQ score (psychological distress) was 3.5 for health care seekers and 2.8 for non-health care seekers-a larger sample would have provided a different result.

One of the most notable features of Talley et al's work is the fact that logistic regression analysis to predict health care seeking for abdominal pain or discomfort within the past 12 months could only explain $4.4 \%$ of the variance. The model concerning health care seeking for any reason within the past 12 months was somewhat more comprehensive $(21.5 \%$ of the variance); this included visible distension (odds ratio $=5.54$ ). It is not clear why abdominal distension should be so important in this respect. This may be related to severity of abdominal pain, but is more likely to be related to health anxiety. ${ }^{7}$ Three childhood abuse items were correlated with distension; such abuse is known to be associated with considerable health anxiety concerning bodily symptoms.

It is clear that further research is required, but useful data are only likely to result from face to face interviews to assess psychosocial data with diary measures of bowel symptoms and health care data obtained from general practitioner records. It does seem that psychological distress and experience of childhood abuse may be related to IBS symptomatology, rather than treatment seeking. One population based study found that childhood abuse was uncommon (6.4-9.4\% of the population) and this related in a linear fashion to the severity of IBS symptoms. ${ }^{11}$

The implications of this work are clear. Clinicians should assess in the clinic (a) severity of IBS symptoms, (b) associated psychological distress, and $(c)$ health anxieties. Clear explanation by the gastroenterologist may reduce health anxiety and subsequent clinic attendance. ${ }^{12}$

F CREED

Department of Psychiarty

Rawnsley Building,

Manchester Royal Infirmary,

Oxford Road, Manchester M13 9WL, UK 
1 Whitehead WE, Bosmajian L, Zonderman AB, Costa PT Jr, Schuster MM. Symptoms of psychologic distress associated with irritable bowel syndrome. Comparison of community and medical clinic samples. Gastroenterology 1988; 95: 709-14.

2 Drossman DA, McKee DC, Sandler RS, Mitchell CM, Cramer EM, Lowman BC, et al. Psychosocial factors in the irritable bowel syndrome: A multivariate study of patients and non patients with irritable bowel syndrome. Gastroenterology 1988; 95: 701-8.

3 Heaton KW, O'Donnell LJ, Braddon FE, Mountford RA, Hughes AO, Cripps PJ. Symptoms of irritable bowel syndrome in a British urban community: consulters and non consulters. Gastroenterology 1992; 102: 1962-7.

4 Heaton $\mathrm{K}$. What makes people with abdominal pain consult their doctor. In: Creed FH, Mayou R, Hopkins A, eds. Medical symptoms unexplained by organic disease. London: Royal Colleges of Physicians and Psychiatrists, 1992: $1-8$.

5 Welch GW, Hillman LC, Pomare EW. Psychoneurotic symptomatology in the irritable bowel syndrome: a study of reporters and non-reporters. $B M \mathcal{F}$ 1985; 291: $1382-4$.
6 Jones R, Lydeard S. Irritable bowel syndrome in the general population. BMF 1992; 304: 87-90.

7 Kettell J, Jones R, Lydeard S. Reasons for consultation in irritable bowel syndrome: symptoms and patient characteristics. Br f Gen Pract 1992; 42: 459-461.

8 Talley NJ, Helgeson SL, Zinmeister AR, Melton LJ III. Gastrointestinal tract symptoms and self reported abuse: A population-based study. Gastroenterology 1994; 107: 1040-9.

9 Mullen PE, Romans-Clarkson SE, Walton VA, Herbison GP. Impact of sexual and physical abuse on women's mental health. Lancet 1988; i: 841-5.

10 Bifulco A, Brown GW, Adler Z. Early sexual abuse and clinical depression in adult life. Br ₹ Psychiatry 1991; 159: 115-22.

11 Longstreth GF, Wolde-Tsadik G. Irritable bowel symptoms in HMO examinees. Prevalence, demographic factors and clinical correlates. Dig Dis Sci 1993; 38: 1581-9.

12 Van Dulmen AM, Fennis JFM, Mokkink HGA, Van der Velden HGM, Bleijenberg G. Doctor-dependent changes in complaint-related cognitions and
anxieties during medical consultations in functional abdominal complaints. Psychol Med 1995; 25: 1011-8. 